\title{
Grappling with ambiguity and contradiction: An examination of the role of reflexivity in coach education research
}

\begin{abstract}
In this article, I analyse the complex process of developing a beginner coach education programme for Ultimate Frisbee (Ultimate) in collaboration with New Zealand Ultimate (NZU) and volunteer coaches within New Zealand's Ultimate community. I construct a reflexive account of this participatory action research project, which sought to generate pedagogically informed coach education that would benefit New Zealand's Ultimate community and meet Sport New Zealand's coaching policies. I focus on particular contextual challenges and opportunities, such as Ultimate's lack of resourcing, and SportNZ's Coach Development Framework, and, in a reflexive manner, consider how my biography impacted this project.
\end{abstract}

\section{Key words}

Coach Education, Coach Development, Ultimate Frisbee, Coaching Pedagogy, Reflexivity

\section{Introduction}

A growing body of scholarship conceptualises coaching and coach education as complex and problematic (e.g., Cassidy et al., 2004; Jones \& Wallace, 2005; Potrac, Brewer, Jones, Armour, \& Hoff, 2000; Trudel \& Gilbert, 2006). Most of this scholarship either critiques existing coach education policies, programmes, and practices (e.g., Cushion, Armour, \& Jones, 2006; Potrac et al., 2000) or develops alternative conceptualizations of coach education through drawing on pedagogical literature from other fields (e.g., Cushion et al., 2003; Jones, 2006). A smaller subset 
of this literature, however, builds on these two approaches, to examine the implementation of alternative coaching pedagogies and curricula in diverse settings, such as University degree programmes (e.g., Demers, Woodburn, \& Savard, 2006; Jones \& Turner, 2006), and with specific National Sport Organizations (NSOs), Regional Sport Organizations (RSOs) and clubs (e.g., Cassidy, Potrac, \& McKenzie, 2006; Culver \& Trudel, 2006).

In this article, I seek to contribute to this latter strand of coach education research, offering a reflexive account of the development of beginner coach education for Ultimate Frisbee in New Zealand. In doing so, I seek to examine the relevance of reflexivity for coach education researchers. Subsequently, I begin this article by considering my approach to reflexivity and my participatory action research methodology. I structure the rest of the article in relation to three key stages relating to reflexivity, namely pre-research, data collection, and data analysis.

\section{Methodology}

Although the reflective coach has been a recent theme in coach education (Knowles, Gilbourne, Borrie \& Nevill, 2001; Knowles, Borrie \& Nevill, 2005), reflexive accounts of coach education research are rare. It is important to recognise that there are multiple types of reflexivity. The most significant distinction separates epistemological reflexivity, as developed by Bourdieu, from personal and textual reflexivity, which have origins in ethnography and poststructural theory (Archer, 2010; Maton, 2003). As Maton explains, epistemological reflexivity emphasizes the relationship between the knower and the known as a strategy for reinforcing claims to 
objective knowledge. Unsurprisingly, this is an approach most strongly valued by post-positivist and critical realist scholars.

Whereas postivists and post-positivists seek to demonstrate that they have not contaminated their research with their own bias, 'new paradigm' researchers (Guba \& Lincoln, 2005) seek to reveal, through personal or textual reflexive analysis, their influence on the research process. These forms of reflexivity contest "the view of knowledge production as independent of the researcher producing it and of knowledge as objective” (Berger, 2015, p. 220). My prime focus in this article is on personal reflexivity. However, personal and textual reflexivity, Macbeth (2001) argues, have considerable similarities as they are both strategies that challenge the notion that qualitative research can generate objective knowledge. Thus, I briefly address textual reflexivity before focusing on personal reflexivity.

Textual reflexivity questions the claims to truth and authority that are made within traditional research texts (Macbeth, 2001). As Denzin (1997) explains, textual reflexivity produces "messy texts" that "are many sited, open-ended... [and] do not indulge in abstract, analytic theorizing” (p. xvii). Textual reflexivity involves experimental scholarly work, such as poetry and plays (e.g., Rinehart, 2010).

Personal reflexivity recognises "that the researcher is a central figure who influences the collection, selection, and interpretation of data” (Finlay, 2002, p. 531). This contrasts with the positivist assumption that the researcher plays a generic, facilitative-as opposed to unique, generative-role in the research process. Importantly, for this project, is recognition that holding a dual role as insiderresearcher inevitably affects responses of participants (Berger, 2015). 
Etherington (2007) defines personal reflexivity as “a tool whereby we can include our 'selves' at any stage, making transparent the values and beliefs we hold that almost certainly influence the research process and its outcomes” (p. 601). For Ezzy (2002), reflexivity reveals how a researcher’s personal experiences “provides data, ideas for theories, contacts for research subjects, it shapes the methodology, conduct of fieldwork and data analysis, and can be an important part of the research report” (p. 154). According to Van Maanen (2011), personal reflexivity often takes the form of a confessional tale, in which "missing data, incompleteness, blind spots, and various other obscurities are admitted into the account” (p. 91).

Earlier versions of this article were couched in a realist tale that was somewhat “aseptic and impersonal” (Van Maanen, 2011, p. 51). My peer reviewers critiqued the disjuncture between realist claims to authority within a purportedly reflexive manuscript. However, writing reflexively is threatening; it requires that I expose vulnerabilities about my research and myself that undercut the claims to authority of my earlier, realist account. For example, I describe below how my failing athletic body (cf., Sparkes, 1999) and diagnosis with diabetes had material effects on this research project.

Yet, Ezzy (2002) and Finlay (2002) warn that excessive reflexivity shifts focus from participants to the researcher and risks an infinite regress of self-analysis. Reflexive research must "strike a balance, striving for enhanced self-awareness but eschewing navel gazing” (Finlay, 2002, p. 541). In this article, I predominantly follow Finlay in offering a reflexive engagement with three stages of my research, namely the preresearch, data collection and data analysis stages. I position this 
reflexive engagement as a confessional tale that sits within my broader account of the development of this coach education programme.

In offering this confessional tale, I draw on notes and reflective journal entries that I took during the project. To promote clarity, I have italicized the sections of this article that are based on my reflective journal entries and notes. However, the process of writing this manuscript also revealed significant insights about earlier phases of the project—including moments when greater reflexivity might have been beneficial— and helped clarify my key findings. Like St. Pierre (2011), I found that many of my insights were formed by "thinking that writing produced" (p. 621, emphasis in original).

Multiple factors influenced my choice of a participatory action research (PAR) methodology. Firstly, the coach education scholarship which I planned to draw on had clearly moved beyond positivist and post-positivist claims to objective knowledge of an independent reality (Guba \& Lincoln, 2005). Relatedly, my existing interpretivist research had assumed "local and specific constructed and coconstructed realities” (Guba and Lincoln, 2005, p. 193). Yet, as this project sought to achieve change I needed a methodology appropriate to this goal. I had a passing familiarity with PAR from my partner's postgraduate study. PAR's goal of achieving "capacity-building within the community involved in the research" (Grant, Nelson, \& Mitchell, 2008, p. 590) had immediate appeal to me.

I hoped PAR would suit my dual role as researcher-insider: Beyond my aim to contribute to coach education scholarship, I was a long-standing member of New Zealand's Ultimate community and wanted the project to benefit players and coaches. In this sense, I hoped that my research would "produce practical knowledge that is 
useful to people in the everyday conduct of their lives” (Reason \& Bradbury, 2008, p. 4). At an individual level, I hoped that I would improve my own coaching practice through this project.

My interest in developing Ultimate coach education did not start "from a desire of changing others 'out there,'” rather it began "from an orientation of change with others” (Reason \& Bradbury, 2008, p. 1, emphasis in orginal). I hoped PAR would disrupt the positioning of the researcher as expert (Fals Borda, 2006). This was important to me as many potential participants had more coaching experience and technical knowledge than me. Yet, I now question whether I was sufficiently critical of PAR and its fit with my research plans. I barely considered whether other research methodologies, such as grounded theory, might have been feasible. This is not to say that I should have adopted an alternative research method, rather I should have been wary of adopting an approach for its intuitive appeal.

Participatory action research is a cyclical process which includes specific phases, namely "observe - reflect - act - evaluate - modify” (McNiff \& Whitehead, 2011, p. 11). I generated an action plan in line with this cycle. My observation phase would include observations of experienced coaches, and interviews with both experienced and aspiring coaches. The reflection phase would analyse this data in relation to coach education scholarship and Sport NZ's Coach Development Framework (CDF) to develop a beginner coach education programme. The action phase would implement this programme. The programme would be evaluated collaboratively and modified for ongoing use. However, the reality of working with volunteers, balancing this research with new work demands, and unforseen changes regarding my own health meant that these cycles did not follow a linear sequence. 
Following McNiff and Whitehead, I found it best to treat my “action plan as a series of prompts, rather than a fixed sequence of steps” (p. 89). In this article, I focus on these challenges and their influence on the research process.

\section{Preresearch stage}

Finlay (2002) suggests reflexivity at the preresearch stage involves the:

need to reflect on both the topic for study and their own relationship to that topic.... At this point, researchers could fruitfully examine their motivations, assumptions, and interests in the research as a precursor to identifying forces that might skew the research in particular directions. (p. 537)

In this section, then, I reflect on the questions I asked as I developed this project, noted in a reflective journal that now seems somewhat sparse. I also seek to reveal questions that I failed to consider. I include relevant background information about New Zealand Ultimate, which as a committed insider, I had access to prior to beginning this project. I begin this section with an excerpt from my reflective journal from the beginning of this project.

\section{Ambivalence}

I like the idea of this project, but I do not like it that much. Brett (pseudonym), my prolific mentor, is encouraging me to apply for funding for it. He is right that it makes sense to start some new research now that I've finished my PhD and it makes sense that I publish something related to pedagogy given the orientation of the programme I work in. But I've spent three years of my life focused on sociology, so 
I'm not completely convinced this is the right way to go. I haven't published anything from my PhD yet, can I balance that task with this one? Brett doesn't think it will be a problem. I'm not so sure. On the other hand, coaching has been a big part of my life for a long time and this project would help me contribute to the Ultimate community.

\section{NZU and the Ultimate Community}

This description is based on my experience as a member of the NZ Ultimate community. As an emergent sport with relatively little infrastructure or bureaucracy, institutional knowledge resided within informal networks of players, playeradminstrators and player-coaches, with little policy or documentation. I have been involved in Ultimate since 2003 in various capacities as a player, coach, regional administrator and tournament director. This level of involvement clearly identifies me as an insider, and while the insider/outsider dichotomy can encourage oversimplification, I have little doubt that my positioning as an insider was facilitated by my status as a white, middle-class, able-bodied, cis-gendered heterosexual male. ${ }^{\mathrm{i}}$ My knowledge of New Zealand Ultimate also developed significantly during my PhD, much of which had been located in the NZ Ultimate community, and included extensive, multi-sited fieldwork, interviews and textual analysis (author).

Ultimate in New Zealand has historically been organized by active players. In contrast to women's flat track roller derby, this is attributable to its short history, rather than a political stance (cf., Beaver, 2012). As a consequence, many volunteers have prioritised playing over administration. Subsequently, despite NZU's executive board being composed of active players, there was little impetus to develop policies, 
or strategic plans to support the sport beyond the short term. NZU's membership model was outdated and its revenue streams struggled to achieve five figures on a consistent basis.

Yet, when I began this project, organizational changes were occurring. Youth leagues had been successfully established in New Zealand's major cities, and weekly adult leagues, including one I had founded, had recently been developed in a number of smaller cities around the country, complementing the longer-established adult leagues in the major cities. Relatedly, I had been involved in workshops that established youth-level trans-Tasman Ultimate tournaments. Shortly after I started this project, NZU began a process of restructuring the roles of the NSO and RSOs, and improving revenue streams.

With these developments, I felt the Ultimate community could benefit from developing the capacity of its coaches, as it had no formal coaching resources. Further, with the development of youth Ultimate, there was growing demand for nonplaying coaches. As a member of this community, I was aware that most discussions about coaching revolved around technical knowledge and that coaching practices were based on the ineffective 'skill and drill' model dominant within many other sports (cf., Cassidy et al., 2004). I hoped that Ultimate might develop coach education that would promote alternative modes of coaching.

There is another element here that I wouldn't write into a realist tale: I began playing Ultimate after burning out from mainstream sport. Traditional team sports stopped being fun for me; and a big part of that was the way we practiced in those sports. I want Ultimate to grow, but I want it to retain something of the alternative spark that appealed to me in the first place (cf., author, Griggs, 2011). I want 
Ultimate to remain self-refereed. I want fun to be part of the game at every level and the traditional model of coaching will make these things harder to maintain.

Although, as I describe below, I was able to articulate the value of this project to the New Zealand Ultimate community, I assumed that my insider status within the community would facilitate this project running smoothly as it had for my $\mathrm{PhD}$. I did not consider that some players might view this project as yet another short-lived, doomed-to-fail project set up by NZU. Whereas my previous research had not been reliant on NZU, I was now seeking to partner with them and should have considered how NZU's involvement might have influenced how others saw the project.

\section{Data Collection}

Drawing on her own use of reflexivity in research, Finlay (2002) argues "reflexive analysis... exposed how the process and outcomes of data collection depend fundamentally on how the research relationship evolves” (p. 538). In this section, then, I offer a reflexive account of my data collection.

\section{Method}

Taking an action research approach, I approached NZU about the possibility of developing a coach education programme. Once NZU confirmed interest, I gained ethical approval and a small grant to cover research expenses from my faculty. After publicizing my project through email lists, I conducted semi-structured interviews with five experienced coaches and three aspiring coaches. The experienced coaches had all coached beginner-level players for a number of years, while the aspiring coaches were experienced players with minimal experience as a coach. The interviews, which were spread over a six-month period, were professionally 
transcribed and returned to the participants for their approval. The interviewsdeveloped in consultation with NZU_covered a range of topics, including participants' awareness of different pedagogical approaches, participants' suggestions about what sets of knowledge were needed in order to competently coach beginners, suggestions about how much progress coaches might reasonably expect beginner teams to make over a six to eight week league, and a range of questions about team management, conflict resolution and athletes’ needs.

Following each interview, I wrote notes in my reflective diary about the interview. I've just interviewed Richard and it was challenging. I appreciate his enthusiasm, and he is experienced coaching novices, but his methods are worrying. Very instructional coaching with lots of him talking and plenty of it not even really related to Ultimate. Limited activity time, particularly for less able athletes and absolute certainty that his methods are the right way to go. Was there something in how I related to Richard in the interview that led him to present himself in such certain terms? We did discuss his feeling of not being accepted by the local Ultimate community. I took that as a sign of trust initially. Now I wonder if it reinforced anxieties he may have had about his coaching.

Although I had over thirty participants volunteer to take part when I publicized my project, when I followed up with these volunteers, I finished up with only eight interviewees. It's hard to say why so many volunteered initially, but have not responded to my follow up emails. If I was actively playing at the moment, I would probably have been able to meet up with other participants at tournaments. But with my slow recovery from my last round of surgery stopping me playing, I am not on the tournament circuit, so am not in regular contact with players from other 
regions. Most of my interviewees are in their thirties and I've known them to varying degrees for a long time. I need to be careful to bring younger people into this project whenever I can. In the meantime, I think I can make it work with eight participants.

My initial plan to observe experienced coaches working with novice players proved to be unfeasible. However, I was able to attend two sessions run by an Australian coach, who was teaching the Australian Flying Disc Association’s (AFDA) level one coaching course to a New Zealand audience. At the first session, I focused exclusively on the coach educator. In the second session, I observed both the coach educator and the learner coaches. I'm writing up notes from the weekend while sitting in the dining room of a hostel, drinking a craft beer and eating a ready-meal from the supermarket. Stuck here overnight after bad weather delayed my flight home. Frustrated with my failing body relegating me to being just a researcher, rather than a researcher-participant.

It is nearly a full year since my last round of surgery and I still struggle to run or change direction. I made an aborted attempt to take part in demonstrations on Saturday and was too sore to try on Sunday. This fieldwork has reinforced how far away I am from being able to play again. While my injured status could have facilitated my focus on my research, my sense of personal loss was a distraction. I still think of myself as a player-coach and a player-researcher rather than a coachresearcher, or coach educator. These challenges aside, the AFDA coaching course has some great TGfU activities components. Other people at the course were excited about my project and seemed happy to be part of it. That's not particularly surprising given that they were willing to give up their weekend to do an Australian course. With 
this fieldwork and some really good interviews in the bank, I now have some momentum in the project.

\section{Data analysis}

Finlay (2002) observes, “rich insights can emerge when one examines one’s own ambivalent responses-it is these ambivalent responses that alert the researcher to the need to be reflexive” (pp. 539-540). Although I had begun the project with some feelings of ambivalence, I became more excited and committed to the project during the data collection phase. Unfortunately, the project stalled as I encountered challenges that delayed data analysis for nearly a full year after completing data collection. The following paragraph is taken from my reflective journal as I attempted to re-engage with this project.

The excitement and momentum that I felt at the end of my fieldwork has long since dissipated. What can I say other than life got in the way? Extra teaching responsibilities, an out-of-the-blue diagnosis of type one diabetes, the birth of my first child and the pressure to publish or perish pushed my focus elsewhere: to my teaching, my health and my new family, to publications from my PhD. Nearly a year has passed since finishing my data collection and this is the first time I've focused on the project. Should I have re-started the project sooner? Perhaps, but the challenges I've faced have been considerable: getting sicker and sicker prior to being diagnosed as diabetic, learning how to count carbs and inject insulin, alarms in the middle of the night to check my blood sugars, uncontrollable lows every time I exercise - and the list could go on. A sense of obligation, rather than excitement is pushing me forward. 


\section{Literature review}

In this section, I briefly review key literature which I sought to put into conversation with my data in order to develop coach education for New Zealand Ultimate. This literature, I hoped, would provide a basis for developing a theoretically informed reading of my research data (Kvale \& Brinkmann, 2009).

\section{New Zealand Coach Policy Climate}

In contrast to much of the international literature, Cassidy and Kidman (2010), offer an optimistic assessment of the policy climate for New Zealand coach education. In their review of policy developments they observed "a move from an accredited and certified, standardised programme, to an ongoing professional development process informed by an applied athlete-centred philosophy (Cassidy \& Kidman, 2010, p. 320). These changes, note Cassidy and Kidman, empower NSOs to develop "learning opportunities and experiences as well as to adapt and adopt learning outcomes in ways that best fit the needs of their own coaching communities” (p. 318).

While they interpret these changes as offering "a paradigm shift” in New Zealand coach education, they qualify this optimism with the observation that "many of these recommendations are 'rarely tried and tested in the field'” (Lyle, 2007, cited in Cassidy \& Kidman, 2010, p. 320). However, two recent studies (Cassidy et al., 2015; Galvan et al., 2012) offer a broadly positive, if qualified, assessment of application of the CDF. While the flexible and progressive nature of the CDF offered me significant scope to develop an innovative coach education programme, I struggled to understand how the broader international literature on coach education could help me develop the programme. 


\section{International literature on coach education}

Over the past fifteen years coach education has replaced mechanistic, linear understandings of coach education replaced with understandings of coaching as a socio-culturally produced pedagogical process. Traditionally, coach education has been delivered in classroom-based block courses, culminating in a written assessment. Such courses have "focused on the delivery of sport science knowledge out of context and assumed a novice-expert coach continuum” (Trudel \& Gilbert, 2006, p. 525). These courses portray coaching “as unproblematic, thus assuming a clear set of achievable sequential goals” (Cassidy et al., 2004, p. 155). Learner coaches do not find coach education courses to be applicable to their own coaching context, due to teacher-centred pedagogies and the abstract nature of these courses (Lemyre, Trudel, \& Durand-Bush, 2007; Nelson, Cushion, \& Potrac, 2012; Piggott, 2011; Wright et al., 2007).

Nevertheless, there are important reasons why such courses are common within coach education. These courses "have the advantages of being packaged, having access to experts, formal assessment procedures, quality assurance measures, and recognition of achievement” (Mallett et al., 2009, p. 330). Within many Western countries, certifying coaches is necessary to reduce the risk of litigation (Robinson, 2015). Moreover, such courses work to minimise time demands being placed on volunteer coaches (Gilbert et al., 2009). As the following excerpt from my reflective journal indicates, I struggled with a sense of contradiction, feeling that a block course would both be necessary and yet be wholly inadequate for progressive coach education. 
Maybe I lack imagination, but it's hard to see how I can develop coach education without block courses. There is a clear expectation from the Ultimate community and NZU that I will develop a block course - this is what they understand coach education to be about and this is what we've had in the past: coaches visiting $N Z$ and putting on skills clinics and the like. But the literature is unequivocal: block courses are ineffective. This puts me into a bind as feel like I can either produce a block course that will be accepted by the Ultimate community as legitimate, or develop an innovative course that coach education scholars might see as pedagogically valid.

Given the weaknesses consistently associated with traditional coach education courses, scholars have explored alternative options to learning within block courses (Cushion \& Nelson, 2013; Trudel, Gilbert, \& Werthner, 2010; Wright, Trudel \& Culver, 2007). Mentoring (Mallett et al., 2009; Nelson et al., 2012), the internet and other informal learning opportunities have been highlighted as having the potential to complement block courses. In particular, significant attention has been paid to Ettiene Wenger’s social theory of learning (Culver \& Trudel, 2006; Culver, Trudel, \& Werthner, 2009; Cushion, 2011; Gilbert et al., 2009; Jones et al., 2011; Trudel et al., 2013) and his notions of Communities of Practice, Networks of Practice and Informal Knowledge Networks. Yet, when considering how beginner level coach education might be improved, Trudel, Culver and Werthner (2013, see also; Mallett et al., 2009) warn of the risks "of falling into the 'more is better' syndrome” (p. 375). 
Implementing new coach education pedagogies

A focus on pedagogy has driven the development of alternative approaches to educating coaches within a range of university programs degrees. These include a competency-based approach to a sport coaching major (Demers et al., 2006) and the development of Problem Based Learning within specific courses at graduate and undergraduate levels (Jones \& Turner, 2006; Jones et al., 2011, Morgan et al., 2012).

Relatedly, working with NSOs, scholars have delivered coach education using pedagogical strategies such as storytelling (Douglas \& Carless, 2008), ethno-drama (Cassidy et al., 2015), and teaching sociological and pedagogical theory to coaches (Cassidy et al., 2006; Galvan et al., 2012). The more I read, the more frustrated I become. Qualitative studies of innovative coach development seem to focus almost entirely on working with experienced coaches, who coach in competitive settings. I find it hard to see how these studies might inform the development of beginner coach education. I've read dozens of articles and cannot see any clear direction to take for this project. I get the critique of block courses, but surely some block courses are better than others. And, if that is the case, then it would be really good to know what differentiates a good course from a bad one.

\section{Data analysis challenges}

\section{Gap between coach education scholarship and context of my project}

Despite the positive policy climate for developing innovative coach education in New Zealand (Cassidy \& Kidman, 2010), I struggled to identify innovative solutions for beginner coach education. What could I hope to achieve in a beginner coach education course? Whether delivered as a block or otherwise, I needed to 
ensure the course was introductory; inevitably basic and not demanding too much time from the lives of the volunteer coaches who would be the audience. As Gilbert et al. (2009) advocate, “we do not believe it is a worthwhile endeavour to require more resource investment (time and money) from youth sport coaches in the form of extensive training requirements” (p. 10).

For a time, I questioned the relevance of much of the literature I had been reading: most innovative pedagogies had been developed in very different contexts to beginner coach education. Pragmatically, how much of this could be applied to this context? Moreover, while scholars had developed clear and justified critiques of block courses, there was also clear acceptance that block courses are likely to remain commonplace in beginner coach education. The obvious question that follows from these two observations is, how might block courses be taught more effectively? Yet, I discovered, this question has not yet been addressed within coach education. Every morning this week, I have worked on my coaching project. It is a dispiriting process of staring at the computer screen, unable to see a way forward. Every morning, I've gotten bored of staring and gone looking for new literature, or re-read something I hadn't taken detailed notes on, but it hasn't led anywhere.

\section{Project delays and organizational instability}

With the delays I described above relating to my health, family and work, I found it hard to maintain an orientation of working with the ultimate community. This time delay was largely out of my control, yet was unequivocally about me, my health, family and employment situation, rather than NZU or my research participants. Unsurprisingly, it disrupted my relationships with NZU and key informants to my 
study. This disruption was compounded by the complete turn over of the membership of NZU. After I submitted a series of reports to the new board stating I had made no progress there was slippage in the board's understanding of my role. As I tried to work through the data analysis phase, it appeared the board's understanding of my role had potentially shifted from coach education policy and programmes, towards the production of a single course, or, perhaps even just a booklet on coaching. This loss of clarity took an extended period of time to resolve and, as the following journal indicates, limited my ability to progress the project.

There are times when I just want to bin this project. It's not working for me and it's not working for NZU. The last two reports I've submitted under their new structure have had no response and I have no idea how much, if any, support I have from the board. There's little point in referring back to the agreement I reached with a prior board. No one is left from that era and everything has been restructured. As annoyed as I am, it's hardly their fault. I am the reason the project has dragged out, and I am the one who approached them about the project.

\section{Managing community expectations and changing levels of commitment}

Given that my research participants were volunteers and already had extensive volunteer commitments in Ultimate, there were limits as to how much I could ask them to contribute to this project. Some clearly regarded me as an expert who should be responsible for making decisions. Others were highly engaged in the data collection phase of my research, yet were unable maintain their involvement as the project overlapped with significant changes in their own lives. David replied to my email about ideas for the coach ed programme. I was really looking forward to what 
he had to say, but he hardly engaged. He's moved on from his role in youth Ultimate and has a young family. He was so excited about this when I did my field work but it's just taken so long to get to this stage he's not responded to the programme like I had hoped he would.

This loss of engagement from participants was partly attributable to my research participants all being based in other cities. Face-to-face contact proved to be the most effective way of retaining contact, yet was hard to achieve, as my diagnosis with diabetes and subsequent exercise-related hypoglycemia added further challenges to my goal of returning to play after multiple surgeries. Unable to play, and with a young family, my involvement as a member of the Ultimate community diminished during much of this project: as I have explained elsewhere (author), membership of the Ultimate community is predicated on high levels of commitment as demonstrated by travelling to weekend long tournaments. Had I been able to play, this may have facilitated the progress of this project.

\section{Data analysis: Resolution}

After an extensive period of time being unable to resolve these contradictory demands, I started to think of my role as creating a coach education programme that was based on pragmatic compromises between the coach education literature, expectations of coaches and of NZU. There was no 'golden bullet' contained in the literature that would 'fix' the challenges of coach education, and it was somewhat naïve of me to assume there could be a simple answer. However, by drawing on literature, I could produce a stronger coach education programme than I would otherwise have achieved. My shift towards pragmatism echoes decision-making in 
other innovations in coach education pedagogy (e.g., Cassidy et al., 2006; Demers et al., 2006; Jones et al., 2011), yet my move towards pragmatic compromises only seems simple or obvious retrospectively: there was no ‘eureka’ moment. Instead, I suggest the extended period of reflection, of thinking with and through ambiguity and contradiction, was not so much a dilemma that needed to be solved as it was a crucial part of developing the coach education programme.

Today I revisited my sources describing alternative pedagogical approaches in coach education, looking specifically for how each one justified their choices about what to include and exclude from their programmes. While Demers et al. (2006) give a detailed justification of their choices, the others offer very little insight into how they made their decisions. Interestingly, discussing the short coach education course they created, Cassidy et al. (2006) observed, "it is useful to remember that reasons are laced with political, theoretical, and personal considerations that influence what appears in a curriculum document and consequently what ends are to be achieved” (p. 147). Is this strugggle over form and structure something other coach educators have experienced but not included in their publications, or is this struggle particular to me as a novice coach educator?

It was during this time that I read and re-read coach education literature, revisited fieldnotes, scoured through SportNZ resources, re-examined my interview transcripts. Moreover, it was because of this extended period of reflection that I had the opportunity to think about this problem beyond coach education literature. Working on other projects, I read Tinning's (2002) call for a 'modest pedagogy,' regularly engaged with St. Pierre’s (2011) methodological argument that, “much data - what we think with when we think about a topic - were identified during 
analysis and not before” (p. 621, emphasis in original) and embraced Kvale’s (Kvale \& Brinkmann, 2009) suggestion that, "creativity is required in putting forth new interpretations” (p. 239). If, as Cassidy et al. (2004) argue, coaching is “a very complex process" which requires that "coach education programmes should engage with, and reflect, the multifaceted, intricate and personal nature of practice” (p. 179), then it should also be recognized that there are few simple decisions to make about what to include or exclude from a coach education programme.

Most significantly, I decided that a block course was needed in order for the Ultimate community to accept the programme as legitimate: Despite the critiques made of block courses within the coach education literature, I needed to be responsive to the expectations of my participants and the broader Ultimate community in order for coach education to be viable (cf., Cassidy et al., 2015). However, I decided that a key challenge would be to ensure that coach education was not limited to this block course. Rather, I hoped the course could serve as an introduction to an ongoing engagement in a range of learning situations involving both peers and experts. In order for this to be possible, it was necessary to build links to the RSOs for regionally appropriate delivery of coach education.

After confirming support from NZU, I created positions for a national coach educator-a role I currently hold—and regional coach educators. I then worked with each RSO to recruit regional coach educators. While teaching regional coach educators how to deliver the course is a central role of the national coach educator, and, concomitantly, delivery of the course is a central task for regional coach educators, the roles are broader than this. The national coach educator is responsible for supporting the ongoing development of regional coach educator. In other words, 
the national coach educator acts as a 'critical friend' to the regional educators, while digital media facilitates communication between regional coach educators.

Relatedly, the regional coach educators are tasked with developing supportive coaching cultures in their regions through developing social events for coaches, promoting further formal and informal education opportunities and using digital media to encourage coaches to engage with the regional coach educator and their fellow coaches. I hope that these measures will support ongoing learning of beginner coaches. As this article focuses on the development of this coach education programme, an evaluation of the implementation of the programme will be required in order to identify strengths and weaknesses.

\section{Conclusion}

In this article I have focused on the challenges of developing pedagogicallyinformed coach education for a small sport within New Zealand. These challenges included negotiating the contextual complexity of what coaches need, want and are able and willing to do, organizational ambiguity and instability affecting the clarity of the project and the impact of my own changing health, family and work circumstances on the project. The first two sets of challenges, those related to the learning needs and interests of coaches, and the constraints that arise when working with a particular institution, such as an NSO, are consistent themes within recent coach education literature (e.g., Nelson et al., 2012; Piggott, 2011). It is important to recognise that although the critique of the dominant model of beginner coach education (e.g., Trudel \& Gilbert, 2006) has been balanced with recognition of the constraints which make block courses likely to remain commonplace (e.g., Mallett et 
al., 2009). Equally as importantly, however, we might recognise that the question of how block courses might be improved or made more effective has yet to be empircally examined.

The third challenge which I faced, the impact of my own biography on the research project, has only very recently been addressed within coach education scholarship. Interestingly, those studies which have adopted an openly reflexive stance have been autoethnographical in nature (e.g., Jones, 2009; Potrac, Jones, Gilbourne, \& Nelson, 2012; Toner, Nelson, Potrac, Gilbourne, \& Marshall, 2012; for an exception see, Bush \& Silk, 2010). They shared the goal of revealing, through evocative personal narrative, the complexities and nuances of the lived experiences of coaches. As Toner et al., observe although the conceptualisation of coaching as a non-linear, complex, social and political activity is well-established and widely shared, much coach education scholarship based on this understanding nevertheless demonstrates “a tendency to present the authors' final constructions and interpretations of experience” (p. 68). As I have sought to demonstrate, the difficulties in interpretation and generation of findings, the challenge of revealing weaknesses about oneself, or one's research which have been discussed in these autoethnographies, are not limited to autoethnographic tales. Rather, these complexities, which require reflexive negotiation throughout the research process, are endemic to the conceptualization of coaching, and coach education as multi-faceted, uncertain, unpredictable and messy.

Subsequently, I have sought to demonstrate the importance of reflexivity throughout the research process. Following Finlay (2002), I have considered reflexivity in relation to the preresearch, data collection and data analysis stages. In 
this manner, rather than presenting a research report as a polished 'finished product', I have laid bare the the challenges and struggles over meaning making that were central to this project, due to the nature of this project and my own biography. This approach to reflexivity, I argue, is consistent with the paradigmatic assumptions of most coach education scholarship I have drawn on in this article. Subsequently, I encourage other researchers within coach education to consider how they might incorporate greater reflexivity into their research reports.

\section{References}

Archer, M. S. (2010). Routine, reflexivity, and realism. Sociological Theory, 28(3), 272-303.

Beaver, T. D. (2012). "By the skaters, for the skaters" the DIY ethos of the roller derby revival. Journal of Sport \& Social Issues, 36(1), 25-49. http://doi.org/10.1177/0193723511433862

Cassidy, T., Jones, R. L., \& Potrac, P. (2004). Understanding sports coaching: The social, cultural and pedagogical foundations of coaching practice. New York, NY: Routledge.

Cassidy, T., \& Kidman, L. (2010). Initiating a national coaching curriculum: A paradigmatic shift? Physical Education \& Sport Pedagogy, 15(3), 307-322. http://doi.org/10.1080/17408980903409907

Cassidy, T., Kidman, L., \& Dudfield, O. (2015). Insights into the process of creating a coach development programme: The opportunities and challenges of 
ethnodrama. Qualitative Research in Sport, Exercise and Health. Advance online publication. http://doi.org/10.1080/2159676X.2015.1012545

Cassidy, T., Potrac, P., \& McKenzie, A. (2006). Evaluating and reflecting upon a coach education initiative: The CoDe of Rugby. Sport Psychologist, 20(2), $145-161$.

Culver, D., \& Trudel, P. (2006). Cultivating coaches’ communities of practice: Developing the potential for learning through interactions. In R. L. Jones (Ed.), The sports coach as educator: Re-conceptualising sports coaching (pp. 97-112). London, UK: Routledge.

Culver, D., Trudel, P., \& Werthner, P. (2009). A sport leader's attempt to foster a coaches’ community of practice. International Journal of Sports Science and Coaching, 4(3), 365-383. http://doi.org/10.1260/174795409789623900

Cushion, C. J. (2011). Etienne Wenger: Coaching and communities of practice. In R. L. Jones, P. Potrac, C. J. Cushion, \& L. T. Ronglan (Eds.), The sociology of sports coaching (pp. 94-107). London, UK: Routledge.

Cushion, C. J., Armour, K. M., \& Jones, R. L. (2003). Coach education and continuing professional development: Experience and learning to coach. Quest, 55(3), 215-230.

Cushion, C. J., Armour, K. M., \& Jones, R. L. (2006). Locating the coaching process in practice: models "for" and "of” coaching. Physical Education and Sport Pedagogy, 11(1), 83-99. http://doi.org/10.1080/17408980500466995

Cushion, C. J., \& Nelson, L. J. (2013). Coach education and learning. In P. Potrac, W. Gilbert, \& J. Denison (Eds.), Routledge handbook of sports coaching (pp. 359-374). Oxon, UK: Routledge. 
Demers, G., Woodburn, A., \& Savard, C. (2006). The development of an undergraduate competency-based coach education program. The Sport Psychologist, 20(2), 162-173.

http://doi.org/10.1080/21640629.2014.953005

Denzin, N. K. (1997). Interpretive ethnography: Ethnographic practices for the twenty-first century. Thousand Oaks, CA: Sage.

Douglas, K., \& Carless, D. (2008). Using stories in coach education. International Journal of Sports Science and Coaching, 3(1), 33-49.

Galvan, H., Fyall, G., \& Culpan, I. (2012). High-performance cricket coaches’ perceptions of an educationally informed coach education programme. AsiaPacific Journal of Health, Sport and Physical Education, 3(2), 123-140. http://doi.org/10.1080/18377122.2012.700692

Gilbert, W., Gallimore, R., \& Trudel, P. (2009). A learning community approach to coach development in youth sport. Journal of Coaching Education, 2(2), 121.

Griggs, G. (2011). “This must be the only sport in the world where most of the players don't know the rules': Operationalizing self-refereeing and the spirit of the game in UK Ultimate Frisbee. Sport in Society, 14(1), 97-110. https://doi.org/10.1080/17430437.2011.530013

Jones, R. L. (Ed.). (2006). The sports coach as educator: Re-conceptualising sports coaching. London, UK: Routledge.

Jones, R. L. (2009). Coaching as caring (the smiling gallery): accessing hidden knowledge. Physical Education and Sport Pedagogy, 14(4), 377-390. https://doi.org/10.1080/17408980801976551 
Jones, R. L., Morgan, K., \& Harris, K. (2011). Developing coaching pedagogy: Seeking a better integration of theory and practice. Sport, Education and Society, 17(3), 313-329. http://doi.org/10.1080/13573322.2011.608936

Jones, R. L., \& Turner, P. (2006). Teaching coaches to coach holistically: Can Problem-Based Learning (PBL) help? Physical Education and Sport Pedagogy, 11(2), 181-202. http://doi.org/10.1080/17408980600708429

Jones, R. L., \& Wallace, M. (2005). Another bad day at the training ground: Coping with ambiguity in the coaching context. Sport, Education and Society, 10(1), 119-134. https://doi.org/10.1080/1357332052000308792

Knowles, Z., Gilbourne, D., Borrie, A., \& Nevill, A. (2001). Developing the reflective sports coach: A study exploring the processes of reflective practice within a higher education coaching programme. Reflective Practice, 2(2), 185-207.

Knowles, Z., Borrie, A., \& Telfer, H. (2005). Towards the reflective sports coach: Issues of context, education and application. Ergonomics, 48(11-14), 17111720.

Kvale, S., \& Brinkmann, S. (2009). InterViews: Learning the craft of qualitative research interviewing (2nd ed). Los Angeles, CA: Sage Publications.

Lemyre, F., Trudel, P., \& Durand-Bush, N. (2007). How youth-sport coaches learn to coach. The Sport Psychologist, 21, 191-209.

Macbeth, D. (2001). On "reflexivity” in qualitative research: Two readings, and a third. Qualitative Inquiry, 7(1), 35-68.

https://doi.org/10.1177/107780040100700103 
Mallett, C., Trudel, P., Lyle, J., \& Rynne, S. (2009). Formal vs. informal coach education. International Journal of Sports Science and Coaching, 4(3), 325364.

Maton, K. (2003). Reflexivity, relationism, \& research: Pierre Bourdieu and the epistemic conditions of social scientific knowledge. Space and Culture, 6(1), 52-65. https://doi.org/10.1177/1206331202238962

McNiff, J., \& Whitehead, J. (2011). All you need to know about action research (2nd ed). Los Angeles, CA: SAGE.

Morgan, K., Jones, R. L., Gilbourne, D., \& Llewellyn, D. (2012). Changing the face of coach education: Using ethno-drama to depict lived realities. Physical Education and Sport Pedagogy, 18(5), 520-533. http://doi.org/10.1080/17408989.2012.690863

Nelson, L., Cushion, C. J., \& Potrac, P. (2012). Enhancing the provision of coach education: The recommendations of UK coaching practitioners. Physical Education and Sport Pedagogy, 18(2), 204-218.

http://doi.org/10.1080/17408989.2011.649725

Piggott, D. (2011). Coaches’ experiences of formal coach education: A critical sociological investigation. Sport, Education and Society, 17(4), 535-554. http://doi.org/10.1080/13573322.2011.608949

Potrac, P., Brewer, C., Jones, R. L., Armour, K., \& Hoff, J. (2000). Toward an holistic understanding of the coaching process. Quest, 52(2), 186-199. http://doi.org/10.1080/00336297.2000.10491709 
Potrac, P., Jones, R. L., Gilbourne, D., \& Nelson, L. (2012). “Handshakes, BBQs, and bullets”: Self-interest, shame and regret in football coaching. Sports Coaching Review, 1(2), 79-92. https://doi.org/10.1080/21640629.2013.768418

Reason, P., \& Bradbury, H. (2008). Introduction. In P. Reason \& H. Bradbury (Eds.), Sage handbook of action research: Participative inquiry and practice (pp. 110). London, UK: Sage.

Rinehart, R. E. (2010). Sport performance in four acts: Players, workers, audience, and immortality. Qualitative Inquiry, 16(3), 197-199.

https://doi.org/10.1177/1077800409351976

Robinson, P. E. (2015). Foundations of sports coaching (Second edition). Oxon, UK: Routledge.

Sparkes, A. C. (1999). The fragile body-self. In A. C. Sparkes \& M. Silvennoinen (Eds.), Talking bodies: Men's narratives of the body and sport (pp. 51-74). Jyvaskyla, Finland: SoPhi.

St. Pierre, E. A. (2011). Post qualitative research: The critique and the coming after. In N. K. Denzin \& Y. S. Lincoln (Eds.), The Sage handbook of qualitative research (4th ed., pp. 611-625). Thousand Oaks, CA: Sage.

Thornton, A. (2004). “Anyone can play this game”: Ultimate Frisbee, identity and difference. In B. Wheaton (Ed.), Understanding lifestyle sport: Consumption, identity and difference (pp. 175-196). Oxon, UK: Routledge.

Tinning, R. (2002). Toward a “modest pedagogy”: Reflections on the problematics of critical pedagogy. Quest, 54(3), 224-240.

http://doi.org/10.1080/00336297.2002.10491776 
Toner, J., Nelson, L., Potrac, P., Gilbourne, D., \& Marshall, P. (2012). From “blame” to "shame" in a coach-athlete relationship in golf: A tale of shared critical reflection and the re-storying of narrative experience. Sports Coaching Review, 1(1), 67-78. https://doi.org/10.1080/21640629.2012.704193

Trudel, P., Culver, D., \& Werthner, P. (2013). Looking at coach development from the coach-learner's perspective: Considerations for coach development administrators. In P. Potrac, W. Gilbert, \& J. Denison (Eds.), Routledge handbook of sports coaching (pp. 375-399). Oxon, UK: Routledge.

Trudel, P., \& Gilbert, W. (2006). Coaching and coach education. In D. Kirk \& D. MacDonald (Eds.), Handbook of physical education (pp. 516-539). London, UK: Sage.

Trudel, P., Gilbert, W., \& Werthner, P. (2010). Coach education effectiveness. In J. Lyle \& C. J. Cushion (Eds.), Sports coaching: Professionalization and practice (pp. 135-152). Edinburgh, UK: Elsevier.

Weisbrod, K. (2016, September 7). From my eyes. Retrieved September 7, 2016, from http://ultiworld.com/2016/09/07/from-my-eyes/

Wright, T., Trudel, P., \& Culver, D. (2007). Learning how to coach: The different learning situations reported by youth ice hockey coaches. Physical Education and Sport Pedagogy, 12(2), 127-144. http://doi.org/10.1080/17408980701282019

${ }^{\mathrm{i}}$ Many members of the Ultimate community pride themselves on Ultimate being an inclusive, diverse sport (Thornton, 2004, author). However, despite such aspirations a range of inequities are evident within the sport and while, for instance, 
some men are beginning to explicitly acknowledge their unearned privileges within the game (e.g., Weisbrod 2016), this is a slow-moving, non-linear process. 